2. To: (Receiving Organization):
Distribution
5. Proj./Prog./Dept./Div.:
PFP Prog. Mgr.

8. Originator Remarks:

For approval and release.

11. Receiver Remarks:

11A. Design Baseline Document? $O$ Yes

ONo
Plutonium Finishing plant

6. Design Authority/Design Agent/Cog. Engr.:

J.C. Sinclair, III
4. Related EDTT No.:

626775 thru 626783

7. Purchase Order No:

N/A

9. Equip./Component No.:

$N / A$

10. System/Bldg./Facility:

N/A

12. Major Assm. Dwg. No.:

N/A

13. Permit/Permit Application No.:

$N / A$

14. Required Response Date:

$N / A$

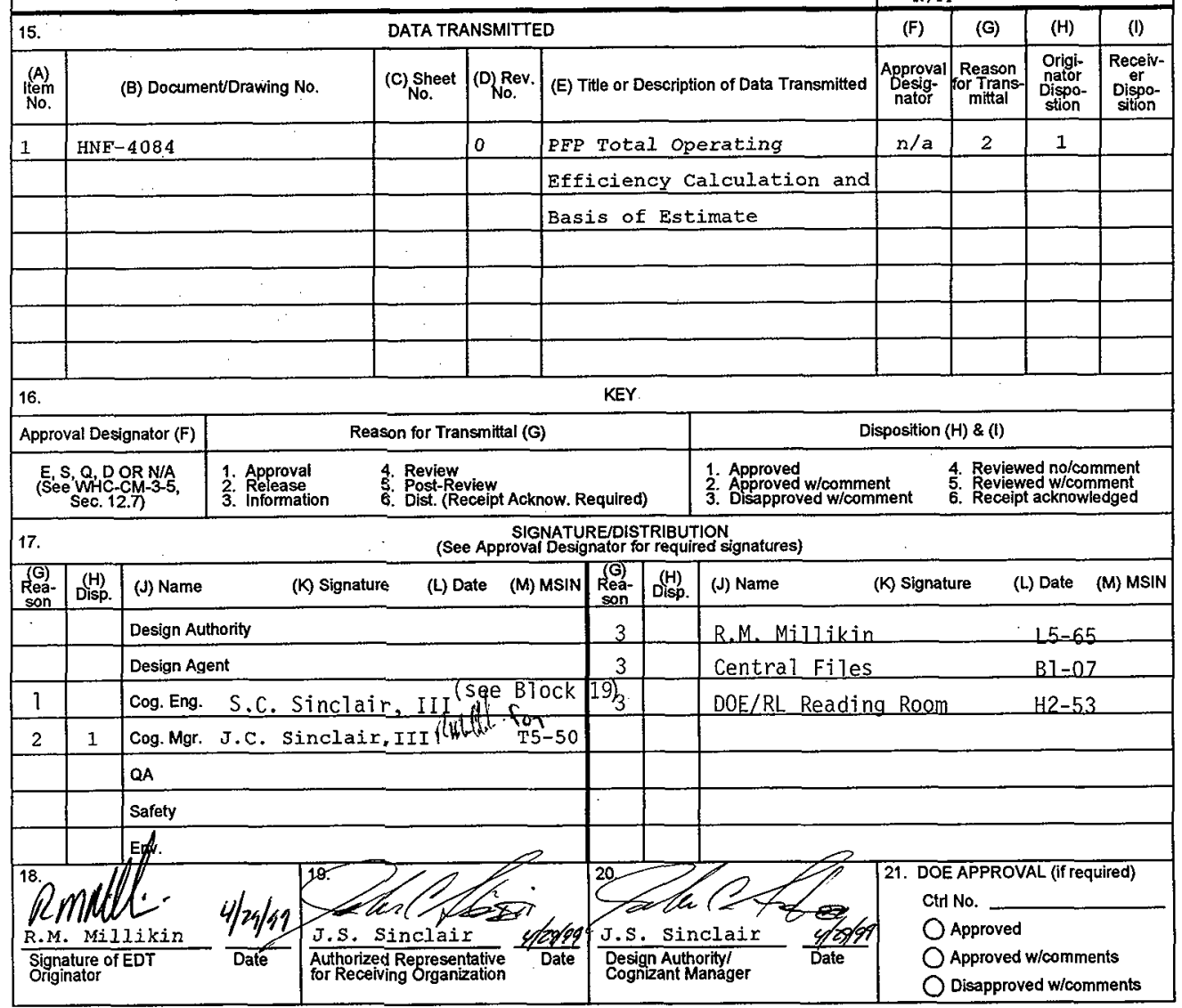




\title{
PFP Total Operating Efficiency Calculation and Basis of Estimate
}

\author{
J.C. Sinclair \\ B\&W Hanford Company \\ Richland, WA 99352 \\ U.S. Department of Energy Contract DE-AC06-96RL13200
}

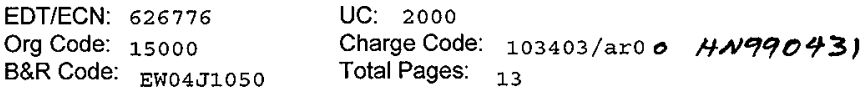

Key Words: PFP, TOE, Total Operating Efficiency, Basis of Estimate

Abstract: This document includes the calculations and basis of estimate fo I the PFP total operating efficiency multiplier used for the FY99 re-baseline of the PFP Iife-cycle baseline. Life-Cycle baseline is found in "Integrated Project Management Plan for the Plutonium Finishing Plant Stabilization and Deactivation Project, HNF-3617.

TRADEMARK DISCLAIMER. Reference herein to any specific commercial product, process, or service by trade name, trademark, manufacturer, or otherwise, does not necessarily constitute or imply its endorsement, recommendation, or favoring by the United States Government or any agency thereof or its contractors or subcontractors.

Printed in the United States of America. To obtain copies of this document, contact: Document Control-Services,

P.O. Box 950, Mailstop H6-08, Richland WA 99352, Phone (509) 372-2420; Fax (509) 376-4989.
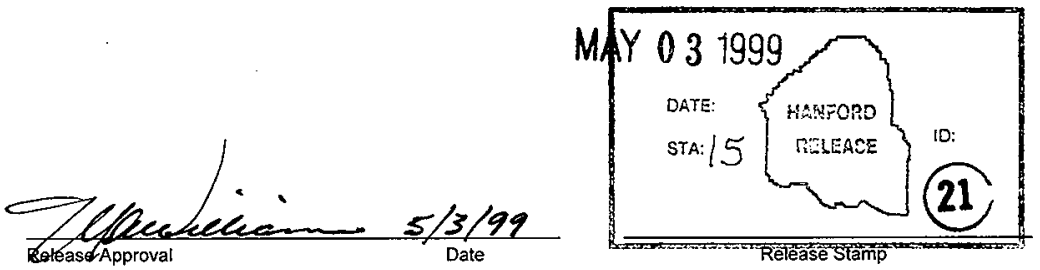

\section{Approved For Public Release}




\section{PFP Total Operating Efficiency Calculation and Basis of Estimate}

HNF-4084, Rev. 0

Prepared by

B\&W Hanford Company and

Fluor Daniel Hanford, Inc.

Prepared for

U.S. Department of Energy, Richland Operations Office 


\section{Table of Contents}

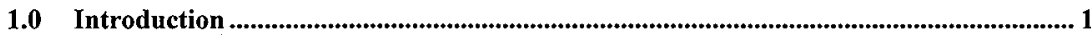

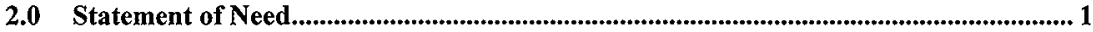

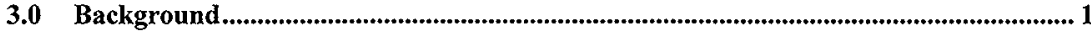

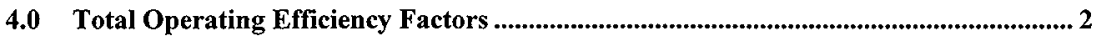

4.1 Continuous Air Monitoring Alarms.................................................................. 2

4.2 Emergency Preparedness Drills ............................................................................... 3

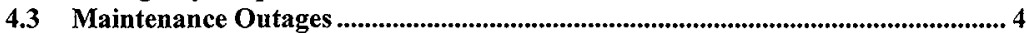

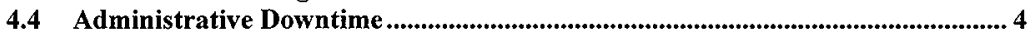

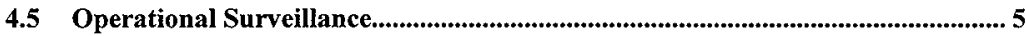

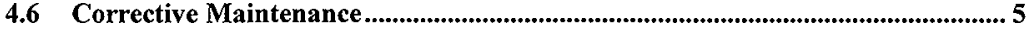

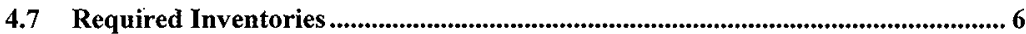

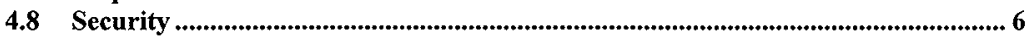

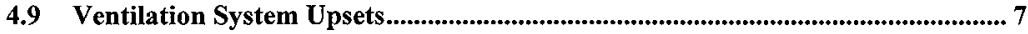

4.10 Airborne Radioactive Area Status ................................................................. 7

4.11 Weekly Shift Start-up and Shut-down.............................................................. 8

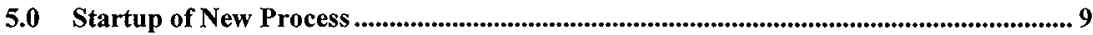




\subsection{Introduction}

The purpose of the PFP Total Operating Efficiency Calculation and Basis of Estimate document is to provide the calculated value and basis of estimate for the Total Operating Efficiency (TOE) for the material stabilization operations to be conducted in 234-5Z Building. This information will be used to support both the planning and execution of the Plutonium Finishing Plant (PFP) Stabilization and Deactivation Project's (hereafter called the Project) resource-loaded, integrated schedule.

\section{$2.0 \quad$ Statement of Need}

The Activity-Based Cost $(\mathrm{ABC})$ estimate approach applies resources and duration to steps within a process flow. However, there is much interference, both planned and unplanned, that can impact the flow of the process or impact the start of new process evolutions. The planned events may include such things as facility outages, facility drills and facility operational and radiological surveillances. Unplanned events result from episodes such as continuous air monitor (CAM) alarms, loss of utilities, and equipment failure. Application of an efficiency factor (TOE) based on documented events allows for the $\mathrm{ABC}$ estimate to remain process driven (assumes 100 percent TOE), allows for the project to obtain a high confidence schedule, and provides a tool for the project manager to actively manage operating efficiency. Once material stabilization is underway, the TOE will be calculated monthly and validated against the TOE assumed during planning. The TOE will be utilized as a tool to identify areas where resources should be focused to provide the maximum benefit in productivity. For example, if equipment failures are causing a 20 percent loss in operating efficiency, significant manpower should be focused on identifying and fixing the causes of the equipment failures. If Operating Safety Report-related equipment testing is causing a five percent loss in operating efficiency, manpower should be focused on trying to identify how to better schedule the tests or reduce the required testing frequency.

\subsection{Background}

The material stabilization processes have been estimated and scheduled using an $\mathrm{ABC}$ approach. Using this approach, each step within the process flow is assigned an estimated duration and resource requirements. The cumulative totals of the duration and resource estimates for each process step define the feed processing rate. The feed processing rate is then used to calculate the overall process duration.

This $\mathrm{ABC}$ estimate has assumed 100 percent efficiency and must have an operating efficiency factor (TOE) applied to it to obtain a realistic schedule. The factors, which contribute to the TOE, need to be well documented and understood. The TOE should reflect actual operating experience to the maximum extent possible. When the TOE is applied to the ABC estimate, a high confidence integrated schedule should result. Historically, the TOE for PFP has been about 60 percent. 


\subsection{Total Operating Efficiency Factors}

The following table, PFP TOE Factors, includes the factors and hours associated with the planned and unplanned events that are calculated into the TOE. Following the table is the basis of estimate for each event.

\section{Table. PFP TOE Factors}

\begin{tabular}{|c|c|c|}
\hline Wharactor & 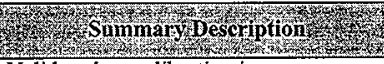 & 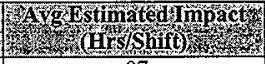 \\
\hline $\begin{array}{l}\text { 4.1 Continuous Air } \\
\text { Monitoring Alarms }\end{array}$ & Valid, radon, calibration issues & .07 \\
\hline $\begin{array}{l}4.2 \text { Emergency Preparedness } \\
\text { Drills }\end{array}$ & $\begin{array}{l}\text { Includes announced, unannounced, and } \\
\text { site wide }\end{array}$ & .06 \\
\hline 4.3 Maintenance Outages & PMs, calibrations, filter changes, etc. & .30 \\
\hline 4.4 Administrative Downtime & Procedure changes, occurrences, etc. & .33 \\
\hline 4.5 Operational Surveillance & $\begin{array}{l}\text { Criticality Alarm System, Instrument } \\
\text { Air, etc. }\end{array}$ & .40 \\
\hline $\begin{array}{l}\text { 4.6 Process Equipment } \\
\text { Corrective Maintenance }\end{array}$ & Equipment troubleshooting, repairs, etc. & .27 \\
\hline 4.7 Required Inventories & $\begin{array}{l}\text { Process shutdown until reconciliation } \\
\text { complete }\end{array}$ & .36 \\
\hline 4.8 Security & Lock downs & .05 \\
\hline 4.9 Ventilation System Upsets & $\begin{array}{l}\text { Unexpected fan shutdowns or control } \\
\text { issues }\end{array}$ & .06 \\
\hline 4.10 ARA Status & $\begin{array}{l}\text { This occurs when seal in or seal out } \\
\text { operations are performed and the ARA } \\
\text { space must be cleared from ARA status. }\end{array}$ & .74 \\
\hline $\begin{array}{l}\text { 4.11 Weekly Shift Start-up } \\
\text { and Shut-down }\end{array}$ & $\begin{array}{l}\text { Monday graveyard process startup and } \\
\text { Friday swing shift shutdown }\end{array}$ & .47 \\
\hline \multicolumn{2}{|c|}{ Total Impact Factor (hrs/Shift) } & 3.11 \\
\hline \multicolumn{2}{|c|}{ Total Operating Efficiency (Percentage) } & $61.1 \%$ \\
\hline
\end{tabular}

\subsection{Continuous Air Monitoring Alarms}

The Continuous Air Monitoring (CAM) Alarm events are in two categories: spurious and real. PFP has an aging CAM system which is maintenance intensive and has numerous spurious alarms. Due to weather conditions and ventilation control, the PFP has historically experienced problems with radon buildup in its processing areas. Due to the potential impact of airborne radiation, each alarm must be responded to as a real event. Both real events and spurious events impact the continuity of the process evolutions including shutting down systems, stabilizing the area and potentially evacuating from the process area. Due to the configuration of the Zone 3 air spaces at PFP, many times a single cam alarm in a room can cause several rooms to be posted as airborne radiation area (ARA) status and resulting in process shutdown. On the other hand, not all CAM alarms are in spaces which impact production. Based upon recent experience, it is estimated that there are about 40 alarms a year in areas that will impact production. 
The assumption is made that the CAM alarms are averaged out over the 52-week period to include weekends.

CAM Alarms responded to -40 alarms per year Assumption of CAM alarms on weekends $-2 / 7=29 \%$

CAM Alarms responded to during the 5-day work week 40 alarms $\times 29 \%=11.6$ alarms $* * * 40$ alarms -11.6 alarms $=28.4$ alarms per year based on 5 day work week.

Average time to clear the effected area -2 hours per Alarm

Total time spent responding to CAM alarms $-28.4 \times 2$ hours $=56.8$ hours per year

Total time spent responding to CAM alarms -56.8 divided by 52 weeks $=1.09$ hours per week

Total time spent responding to CAM alarms $-1.09 \mathrm{hrs} / \mathrm{wk}$ divided by $15 \mathrm{shifts} / \mathrm{wk}=.07$ hours per shift

\section{IMPACT $=.07$ hours per shift}

\subsection{Emergency Preparedness Drills}

Emergency preparedness is essential for training of personnel in the event of a plant wide emergency or process upset. Drills consist of a pre-drill briefing for management personnel and system experts to act as observers and controllers in the drill scenario. These pre-drill briefings are required to ensure the adequate radiological and security controls are in place to allow the drill to be successful and keep the plant in a safe operating condition. This briefing takes these individuals away from their normal operating mode in support of the drill activity. The average drill set up and completion time is four hours for process upsets (tabletop or process specific drills) and as many as six hours for plant-wide or site-wide emergency drills involving the entire facility. At the conclusion of the drill, a critique meeting is held with all participants of the drill. Personnel are required by FSP-PFP-1121, Plutonium Finishing Plant Training Administration,Section 22 , Step 4.7 , to participate in one drill per year to stay proficient. The facility is scheduled to run as many as 80 Emergency Preparedness Drills for 1999. However, not all of these directly affect processing.

Assumption is made that the affected employees will be working an eight-hour shift, Monday through Friday.

Drills impacting processing -12 per year

Time required participating in a drill -4 hours 
Drills actually participated in per plant history interviews -12 drills per person $\times 4$ hours

$=48$ hours

Drills per week -48 hours divided by 52 weeks $=0.92$ hours per week

Drills per 8 hour shift $-0.92 \mathrm{hrs} / \mathrm{wk}$ divided by 15 shifts $/$ wk $=.06$ hours per shift

\section{IMPACT $=.06$ hours per shift}

\subsection{Maintenance Outages}

Maintenance outages for stabilization activities require routine planned maintenance to ensure the proficiency of processing activities. These include process specific outages for routine maintenance such as preventative maintenance (PM), calibration of equipment and filter changeouts that are process specific and plant-wide routine maintenance such as ventilation outages, electrical outages and preventive maintenance that can effect the entire facility. These outages are planned and scheduled to be performed to limit the impact to processing activities. This data is derived from interviews with both past and present PFP Maintenance planners.

Assumption is made that maintenance is performed Monday through Friday in eight-hour shift increments.

Outage History average from past schedules and plant personnel interview activities 208 hours per year

Outage History average -208 hours divided by 52 weeks $=4$ hours per week.

Outage History average $-4 \mathrm{hrs} / \mathrm{wk}$ divided by $15 \mathrm{shifts} / \mathrm{wk}=0.3$ hours per shift

IMPACT $=0.3$ hours per shift

\subsection{Administrative Downtime}

Various administrative issues occur during the year that impact operations. These include: required procedure changes, logistical issues which limit material movement, occurrences, mislabeled containers, process upsets, etc. Impact of individual incidents can be from as little as a few hours to weeks depending upon the scope and complexity of the issue. As work increases the frequency of most of these go up proportionally. It is estimated that there are two or three administrative issues per week with an average impact of two hours per issue.

Issues per year $=2$ per week $\times 26$ weeks +3 per week $\times 26$ weeks $=130$ issues per year

Time required per issue -2 hours 
Total time per year spent on issues -130 issues $\times 2$ hours $=260$ hours per year

Total time per week spent on issues -260 hours divided by 52 weeks $=5$ hours per week

Total time per 8 hour shift spent on issues -5 hrs/wk divided by 15 shifts $/$ wk $=0.33$ hours per shift

\section{IMPACT $=.33$ hours per shift}

\subsection{Operational Surveillance}

Operational Surveillances, such as Criticality Alarm Panel (CAP) system PMs/Surveillances are performed during day shift. The surveillance activities do not typically interfere with operation of process equipment. However, if during the surveillance a problem is identified, operations will remain shutdown until the successful conclusion of the surveillance, including review and sign-off for OSR-related equipment. Repairs that impact operations are estimated to occur onece every two weeks, and usually require about 12 hours to service.

Operation impact of surveillance -6 hours per week

Surveillance impact -6 hours/week divided by 15 shifts/week $=0.4$ hours per shift

\section{IMPACT $=.4$ hours per shift}

\subsection{Corrective Maintenance}

Corrective maintenance occurs when a piece or pieces of the equipment fail to perform. When this occurs, the operational authority contacts process engineering to trouble shoot the problem and identify corrective maintenance. After identification of the problem, the operations authority writes a work order to repair the failed equipment. The work order then goes to planning and scheduling and a priority is put on the work to be performed. This process can take as little as 30 minutes or may take as many as several days depending on parts availability, craft support and plant priority. Due to increased electrical energy safeguards and radiological control requirements, corrective maintenance is a challenge to schedule and complete in a timely fashion. Plant history and interviews indicate down time in hours lost due to corrective maintenance is 215 hours per year. Given that not every process is the same in complexity or technical maturity, this factor may be adjusted on a project basis. The data presented below represents what is typically seen at PFP.

Assumption is made that the work will be performed Monday through Friday on an eighthour shift. 
Hours per year in corrective maintenance -215 hours

Hours per week in corrective maintenance -215 hours divided by 52 weeks $=4.13$ hours per week

Hours per shift in corrective maintenance $-4.13 \mathrm{hrs} / \mathrm{wk}$ divided by $15 \mathrm{shifts} / \mathrm{wk}=.27$ hours per shift

\section{IMPACT $=0.27$ hours per shift}

\subsection{Required Inventories}

Inventory requirements include bi-monthly and annual inventories as directed by the U.S. Department of Energy Safeguards and Security. These inventories impact the processing operations due to the inability to move special nuclear material (SNM) when the inventory is being conducted. The bi-monthly inventory shuts down operations for two days (four shifts) while the annual inventory shuts processing down for a week.

Assumption is made that the Inventories will be conducted Monday through Friday on an eight-hour shift basis.

Total hours of Inventory hold -5 bi-monthly $\times 4$ shifts +15 shifts annual $=35$ shifts $\times 8$ hours $=280$ hours

Total hours of Inventory hold per week -280 hours divided by 52 weeks $=5.4$ hours per week

Total hours of Inventory hold per shift $-5.4 \mathrm{hrs} / \mathrm{wk}$ divided by $15 \mathrm{shifts} / \mathrm{wk}=.36$ hours per shift

\section{IMPACT $=.36$ hours per shift}

\subsection{Security}

PFP has numerous alarms as part of the Security and Safeguards system used to protect the SNM. Alarms occur with some regularity due to inadvertent contact from personnel or other reasons. Most of the alarms can be quickly cleared, or they have no direct impact on operations. However, a small percentage of the alarms do impact operation and must be accounted for.

Assumption is made that the lockdowns are averaged over a 52-week period that includes weekends.

Number of lockdowns per year impacting processing - 35 
Number of hours on average per lock down -1 hour

Number of total hours of lockdown for facility -35 hours $\mathrm{x} 1=35$ hours/year

Number of total hours of lockdown per week $-35 \mathrm{hrs} / \mathrm{yr}$ divided by 52 weeks $=.67$ hours per week

Number of total hours of lockdown per shift $-.67 \mathrm{hrs} / \mathrm{wk}$ divided by $15 \mathrm{shifts} / \mathrm{wk}=.05$ hours per shift

\section{IMPACT $=.05$ hours per shift}

\subsection{Ventilation System Upsets}

Ventilation system upsets can occur without notice due to the sensitive nature of the PFP ventilation design and requirements. High winds or equipment failure can cause the ventilation system to fail and activate back up steam turbines that put the facility in a minimum-safe configuration. When this occurs, all radiological and glovebox work in the Zone 3 area stops. This, in turn, shuts down the processing operations due to the inability to move radioactive material.

Total ventilation outages per year -6

Total average hours per event -8 hours

Total average hours per year -6 events $\times 8$ hours $=48$ hours

Total average hours per week -48 hours divided by 52 weeks $=.92$ hours per week

Total average hours per day $-.92 \mathrm{hrs} / \mathrm{wk}$ divided by $15 \mathrm{shifts} / \mathrm{wk}=.06$ hours per shift

\section{IMPACT $=.06$ hours per shift}

\subsection{Airborne Radioactive Area Status}

Operations in the process of sealing in and sealing out SNM for stabilization processing must change the radiological condition of the rooms impacted by putting the room(s) on Airborne Radioactive Area (ARA) status. Not only is the room with the activity impacted, with the current airflow conditions in PFP, all 'downstream' rooms must also go on respiratory protection. This activity allows the staff to perform the seal in or seal out operations, but also has a negative productivity impact on other affected rooms. The impact to the process comes when attempting to clear the room from ARA status. The time required to take a room off of ARA status by radiological control can take hours to sometimes days depending on the atmospheric conditions of the facility. Figures are derived from interviews with current radiological engineers at PFP. 
The rotating shifts perform nominally 2 days of ARA activity per month based on roll up of individual activities $=2$ days per month $\times 12$ months $=24$ days per year.

Average days area on ARA $=24$ days $\times 24$ hour shifts $=576$ hours per year

Average hours area on ARA $=576$ hours divided by 52 weeks $=11.08$ hours/week

Average hours area on ARA $=11.08 \mathrm{hrs} / \mathrm{wk}$ divided by $15 \mathrm{shifts} / \mathrm{wk}=0.74$ hours per shift

\section{IMPACT $=0.74$ hours per shift}

\subsection{Weekly Shift Start-up and Shut-down}

Weekly shift start-up and shutdown operations take into account several activities that must be performed prior to the process actually starting up and operating. These activities include weekly safety meeting, facility logbook reviews, procedure review for changes and, checking out keys to access rooms. The Central Alarm Station must be called to take affected processing rooms off alarm status and personnel must be cleared through the access control entry system (ACES) station to ensure all training requirements are met to allow entry into the radiological zone. After entering the radiological zone and material access area (MAA), the operators must don anti-contamination clothing to enter the radiological zone. These are all the items required prior to starting up the process operations and once in the processing area pre-valving and preheating of some operations are required prior to full operations. A subset of these activities must also be completed when the process is shut down at the end of the week. In addition, there is a loss of efficiency due to the cycle times of processes which frequently will cause some dead time at the end of the week because there is not sufficient time to get an additional run completed.

Assumption is made that these activities occur on a Monday and Friday for calculation of T.O.E.

Estimated required time to complete the above activities:

Start up operations total $=3$ hours per week

Shut down operations and cycle time effects $=4$ hours per week

Total time required to complete start up and shut down ops $-7 \mathrm{hrs} / \mathrm{wk}$ divided by 15 shifts/wk $=0.47$ hours per shift

IMPACT $=0.47$ hours per shift 


\subsection{Startup of New Process}

It is well known that during the initial weeks following the start-up of new processes, the operating efficiency is much lower than the operating efficiency would predict. There are five primary contributors: procedure revisions, oversight scrutiny, operator inexperience, mechanical problems and material handling and movement problems. Recent experience at Rocky Flats Plant (Denver, Colorado) has shown that this start up period lasts from six weeks to three months, depending upon the complexity of the process and the ability to rapidly correct the issues. Initial startup efficiencies at Rocky Flats varied, but were generally $25-50$ percent during the first weeks with gradual improvement to the expected TOE over the first few months. This effect has not been included in this TOE calculation because the startup efficiency is considered in the CEIS data sheets and schedule logic for the specific processes. 

and Basis of Estimate

This page intentionally left blank. 